\title{
ANALISIS PELAKSANAAN REKRUTMEN DAN SELEKSI CALON KARYAWAN BARU DI RSIA KENDANGSARI MERR SURABAYA
}

\author{
Anis Fitri Aulia \\ Departemen Administrasi dan Kebijakan Kesehatan \\ Fakultas Kesehatan Masyarakat, Universitas Airlangga \\ Email: anisfitriaulia@yahoo.com
}

\begin{abstract}
Recruitment and selection are the most important part in the formation of quality human resources. The effectiveness of recruitment and selection will determine the success of employee performance in the future. The aim of this study was to learn the implementation of recruitment and selection of prospective employees at RSIA Kendangsari Merr Surabaya. The method of this study is observational by using qualitative data in the form of primary data and secondary data. The results of this study found that the recruitment method in RSIA Kendangsari Merr consists of promotion, rotation, job posting, advertising, websites, employee recommendations, labor department, labor placement agencies, and job training programs. While the selection process in RSIA Kendangsari Merr consists of administrative selection, written tests, interview tests, psychological tests, credentials, health checks, and work agreements for a 3-month trial period. The conclusion of this study that all recruitment methods in RSIA Kendangsari Merr Surabaya are in accordance with the internal and external methods of recruitment methods, and the selection process is in accordance with the rules of the selection stages. Recommendation for RSIA Kendangsari Merr is to provide additional recruitment method, it is job bidding. Job bidding can be applied at RSIA Kendangsari Merr Surabaya by offering job positions to employees who are competent with career development to meet certain specifications required. Besides being beneficial for motivation and career development of $H R$, it also minimizes the costs of recruitment and selection sourced from external organizations.
\end{abstract}

Keywords: Employee, Human Resource, Recruitment, Selection

\begin{abstract}
ABSTRAK
Rekrutmen dan seleksi merupakan bagian terpenting dalam pembentukan sumber daya manusia yang berkualitas. Efektiitas rekrutmen dan seleksi akan menentukan keberhasilan kinerja karyawan di masa mendatang. Tujuan dari penulisan ini adalah untuk mempelajari pelaksanaan rekrutmen dan seleksi calon karyawan di RSIA Kendangsari Merr Surabaya. Metode dari studi ini adalah observasional dengan menggunakan data kualitatif berupa data primer dan data sekunder. Hasil dari penelitian ini didapatkan bahwa metode rekrutmen yang ada di RSIA Kendangsari Merr Surabaya terdiri dari promosi, rotasi, pengumuman pekerjaan, iklan, situs web resmi, rekomendasi karyawan, departemen tenaga kerja, agen penempatan tenaga kerja, dan program pelatihan kerja. Sedangkan proses seleksi yang ada di RSIA Kendangsari Merr Surabaya terdiri dari seleksi administratif, tes tulis, tes wawancara, tes psikologi, kredensial, pemeriksaan kesehatan, dan perjanjian kerja untuk masa percobaan 3 bulan. Kesimpulan dari studi ini bahwa semua metode rekrutmen di RSIA Kendangsari Merr Surabaya telah sesuai dengan kaidah metode rekrutmen baik
\end{abstract}


internal maupun eksternal, dan proses seleksi telah sesuai dengan kaidah tahap seleksi. Rekomendasi untuk RSIA Kendangsari Merr adalah memberikan tambahan pilihan metode rekrutmen yaitu job bidding. Job bidding dapat diterapkan di RSIA Kendangsari Merr Surabaya dengan menawarkan posisi pekerjaan kepada karyawan yang kompeten dengan pengembangan karir untuk memenuhi spesifikasi tertentu yang diperlukan. Selain bermanfaat bagi motivasi dan pengembangan karir SDM, juga meminimalkan biaya rekrutmen dan seleksi yang bersumber dari eksternal organisasi.

Kata kunci: Karyawan, Rekrutmen, Seleksi, Sumber Daya Manusia

\section{PENDAHULUAN}

Berdasarkan Undang-Undang Nomor 44 tahun 2009 tentang Rumah Sakit menjelaskan bahwa rumah sakit adalah institusi pelayanan kesehatan yang menyelenggarakan pelayanan kesehatan perorangan secara paripurna yang menyediakan pelayanan rawat inap, rawat jalan dan gawat darurat. Pelayanan paripurna yang dimaksud adalah pelayanan yang mencakup pelayanan promotif, preventif, kuratif dan rehabilitatif. Rumah Sakit sebagai sebuah organisasi yang menyediakan pelayanan jasa secara paripurna memiliki tujuan untuk tumbuh dan berkembang. Dalam suatu organisasi, sumber daya manusia memiliki peran yang besar sebagai penggerak dan penentu berlangsungnya proses produksi dan segala aktivitas organisasi. Sehingga manajemen sumber daya manusia sangat penting dilakukan oleh organisasi untuk mendapatkan sumber daya manusia yang berkualitas.

Manajemen sumber daya manusia mengatur peranan sumber daya yang dimiliki oleh individu secara efektif dan efisien serta menghasilkan produktivitas yang maksimal sehingga tujuan organisasi dapat tercapai.
Kegiatan manajemen sumber daya manusia yang penting dalam mendapatkan sumber daya yang berkualitas yaitu proses rekrutmen dan seleksi calon karyawan baru.

Rekrutmen dan seleksi adalah bagian utama dari strategi organisasi dalam sumber daya manusia, dengan mengidentifikasi dan mengumpulkan orang-orang yang diperlukan untuk organisasi untuk bertahan hidup dan berhasil dalam jangka pendek hingga menengah. Tujuan dasar rekrutmen adalah untuk menciptakan kumpulan kandidat yang memenuhi syarat untuk memungkinkan pemilihan kandidat terbaik untuk organisasi, dengan menarik lebih banyak karyawan untuk diterapkan dalam organisasi, sedangkan tujuan dasar dari proses seleksi adalah memilih kandidat yang tepat untuk mengisi berbagai posisi yang dibutuhkan dalam organisasi. ${ }^{1}$

Proses rekrutmen dan seleksi yang tepat dapat memengaruhi kinerja karyawan di masa mendatang. Kinerja karyawan dan kepuasan kerja karyawan juga mempengaruhi pergantian karyawan. Motivasi karyawan untuk bertahan di perusahaan atau berhenti bekerja ditentukan oleh kinerja dan kepuasan kerja karyawan. 
Kemudian tahap pembentukan, pemeliharaan, dan penghentian karyawan menjadi siklus kerja dalam sumber daya manusia yang saling memengaruhi.

Tingkat turnover di RSIA Kendangsari Merr Surabaya pada 2016 adalah 21\%, pada $201713 \%$, sementara selama 2018 berjalan dari Januari hingga Agustus ada 12 karyawan mengundurkan diri dari total 129 karyawan. Jumlah ini bukan jumlah yang kecil, sehingga untuk mempertahankan siklus kerja yang baik pergantian karyawan harus dilanjutkan. Perlu ada proses rekrutmen dan seleksi yang tepat untuk menggantikan posisi yang kosong atau menambah karyawan ke unit kerja yang memiliki beban kerja besar. Tujuan dari penulisan ini adalah untuk menganalisis pelaksanaan rekrutmen dan seleksi calon karyawan baru di RSIA Kendangsari Merr Surabaya.

\section{METODE PENELITIAN}

Metode penelitian ini adalah kualitatif dengan menganalisis perbandingan antara metode rekrutmen dan proses seleksi sesuai dengan teori atau aturan referensi dengan metode rekrutmen dan proses seleksi yang dilakukan di RSIA Kendangsari Merr Surabaya.

Pengumpulan data terdiri dari data primer dan data sekunder. Data primer diperoleh dengan wawancara langsung dengan kepala unit SDM dan kepala departemen SDM dan hukum dari mereka tentang rekrutmen dan seleksi di RSIA Kendangsari Merr Surabaya. Data sekunder diperoleh dari dokumen, pedoman, atau riwayat tentang rekrutmen dan seleksi di RSUD Kendangsari Merr Surabaya. Setelah mendapatkan data, analisis dilakukan dengan referensi yang ada.

\section{HASIL DAN PEMBAHASAN}

Proses rekrutmen dan seleksi adalah bagian dari perencanaan sumber daya manusia organisasi dan terdiri dari beberapa langkah yang bertujuan untuk memilih yang terbaik dari para kandidat. Langkah-langkah ini adalah perkiraan kebutuhan staf, pembuatan daftar pelamar, pengumpulan data setelah evaluasi dan pilihan calon karyawan baru yang memenuhi syarat untuk direkrut.

Sebelum pelaksanaan rekrutmen dan seleksi, RSIA Kendangsari Merr membuat rencana untuk jumlah karyawan dan spesifikasinya dalam bentuk pola ketenagaan. Setiap unit kerja menghitung kebutuhan tenaga kerja menggunakan analisis WISN. Unit kerja yang membutuhkan staf tambahan atau personel pengganti dari karyawan yang keluar kemudian mengajukan permohonan penambahan tenaga kerja kepada direktur untuk merekrut dan memilih calon karyawan baru. Menurut teori, perekrutan dimulai dengan perencanaan sumber daya manusia dan analisis pekerjaan. $^{2}$ 
Dalam panduan penerimaan staf RSIA Kendangsari Merr Surabaya, dijelaskan bahwa dasar pelaksanaan rekrutmen dan seleksi adalah adanya uraian tugas, spesifikasi pekerjaan, dan analisis pekerjaan. Ketiga elemen ini membentuk dasar untuk membuat pola ketenagaan RSIA Kendangsari Merr Surabaya yang dibuat dan diperbarui pada awal setiap tahun. Pola ketenagaan yang telah dibuat menampilkan hasil bahwa apakah unit SDM perlu menambah karyawan atau tidak sehingga menjadi rencana untuk perekrutan dan seleksi calon karyawan baru di RSIA Kendangsari Merr Surabaya. Rekrutmen dan seleksi calon karyawan baru di RSIA Kendangsari Merr Surabaya telah diatur dalam kebijakan rumah sakit, pedoman rekrutmen dan seleksi, dan SOP rekrutmen karyawan baru.

Rekrutmen dan seleksi dalam suatu organisasi adalah bagian integral dari keseluruhan proses pengelolaan dan perencanaan sumber daya manusia dalam organisasi. Dengan demikian, terkait erat dengan proses manajemen sumber daya manusia lainnya, misalnya, desain pekerjaan, pengembangan sumber daya manusia, penilaian kinerja dan manajemen, sistem penghargaan, perencanaan karir, promosi dan transfer. ${ }^{3}$ Keberhasilan proses rekrutmen dan seleksi adalah strategi yang disiapkan organisasi untuk mengidentifikasi dan memilih kandidat terbaik untuk pengembangan sumber daya manusia yang dimiliki. $^{4}$
Agar suatu organisasi dapat mempertahankan keunggulan kompetitif, setiap langkah dalam proses rekrutmen dan seleksi membutuhkan waktu dan pertimbangan yang cermat. Keputusan yang dibuat dalam tahap rekrutmen dan seleksi akan berdampak pada perusahaan di masa depan. Keputusan buruk yang dibuat dalam proses seleksi dapat menimbulkan biaya serius bagi suatu organisasi. Oleh karena itu, rekrutmen dan seleksi adalah proses utama dalam strategi manajemen sumber daya manusia. ${ }^{5}$

\section{Analisis Rekrutmen}

Rekrutmen adalah proses organisasi dalam mencari karyawan yang tepat untuk pekerjaan yang tepat. ${ }^{6}$ Rekrutmen adalah proses menemukan kandidat potensial untuk lowongan organisasi yang aktual atau sebagai antisipasi. Dari sudut pandang lain, rekrutmen adalah kegiatan menghubungkan dan menyatukan organisasi yang memiliki pekerjaan untuk diisi dengan pelamar yang mencari pekerjaan. ${ }^{7}$ Proses rekrutmen tidak berhenti dengan pelaksanaan penarikan calon karyawan dan pemilihan kandidat yang sesuai, tetapi melibatkan mempertahankan dan mengembangkan karyawan yang dipilih. ${ }^{8}$

Rekrutmen di RSIA Kendangsari Merr Surabaya dapat bersumber dari internal dan eksternal, sesuai dengan teori bahwa rekrutmen dikategorikan ke dalam dua sumber yang berbeda, yaitu dari lingkungan internal perusahaan dan lingkungan eksternal. ${ }^{9}$ 
Sumber internal adalah sumber daya manusia yang diterima dari organisasi itu sendiri. Organisasi mendapatkan karyawan baru dengan mencari karyawan di organisasi untuk ditempatkan di posisi tertentu. Keuntungan dari proses ini adalah biaya yang tidak terlalu mahal, dapat mempertahankan loyalitas bisnis yang lebih besar dan dorongan antara karyawan perusahaan dan dapat membiasakan karyawan dengan suasana perusahaan sendiri. Sementara kelemahan dari proses ini adalah pembatasan bakat karyawan lain, mengurangi peluang dan dapat meningkatkan perasaan puas terhadap karyawan. Menurut Darkoh, rekrutmen dengan sumber internal terdiri dari promosi, transfer, job posting, dan job bidding. ${ }^{4}$
Sumber eksternal adalah sumber daya manusia yang diterima dari luar rumah sakit. Keuntungan dari sumber rekrutmen eksternal adalah perusahaan dapat memilih dan menentukan calon karyawan yang benar-benar di bidangnya, dan membawa sistem kerja baru yang lebih baik daripada yang sudah ada. Namun, kelemahan dari sumber rekrutmen eksternal adalah bahwa peluang promosi berkurang bagi karyawan dalam perusahaan sehingga kinerja karyawan kurang, dan ada biaya penarikan yang besar dan membutuhkan waktu yang relatif lama. Menurut Darkoh, metode rekrutmen dengan sumber eksternal terdiri dari iklan, e-recruitment, employee referrals, kantor tenaga kerja, agen tenaga kerja, lembaga pendidikan dan pelatihan. ${ }^{4}$

Tabel 1. Perbandingan Metode Rekrutmen Menurut Darkoh (2014) Dengan Metode Rekrutmen di RSIA Kendangsari Merr Surabaya

\begin{tabular}{|c|c|c|c|}
\hline Referensi & RSIA Kendangsari Merr & Ada/ tidak ada & Keterangan \\
\hline Promotion & Promosi & Ada & terdapat SPO \\
\hline Transfer & Rotasi & Ada & terdapat SPO \\
\hline Job posting & Job posting & Ada & $\begin{array}{l}\text { terdapat Panduan } \\
\text { dan SPO }\end{array}$ \\
\hline Job bidding & - & Tidak ada & tidak ada \\
\hline Advertisement & Iklan pada sosial media & Ada & $\begin{array}{l}\text { terdapat Panduan } \\
\text { dan SPO }\end{array}$ \\
\hline E-Recruitment & Website resmi & Ada & $\begin{array}{l}\text { terdapat Panduan } \\
\text { dan SPO }\end{array}$ \\
\hline Employee referrals & Rekomendasi karyawan & Ada & terdapat Panduan \\
\hline Labour offices & Departemen tenaga kerja & Ada & terdapat Panduan \\
\hline Employment agencies & $\begin{array}{l}\text { Agen penempatan tenaga } \\
\text { kerja }\end{array}$ & Ada & terdapat Panduan \\
\hline $\begin{array}{l}\text { Education \& training } \\
\text { establishment }\end{array}$ & $\begin{array}{l}\text { Program pelatihan kerja, } \\
\text { Institusi Pendidikan dan } \\
\text { Pelatihan }\end{array}$ & Ada & terdapat Panduan \\
\hline
\end{tabular}


Berdasarkan Tabel 1 dapat dilihat bahwa semua metode rekrutmen di RSIA Kendangsari Merr Surabaya sudah sesuai dengan yang ada di referensi, tetapi ada satu metode rekrutmen yang belum ada, yaitu job bidding.

Promosi mengacu pada mempromosikan atau meningkatkan karyawan yang sudah ada dalam daftar karyawan dan berkontribusi pada kinerja organisasi. Promosi menggeser karyawan ke posisi yang lebih tinggi dengan tanggung jawab, fasilitas, status dan gaji yang tinggi. Promosi menandakan imbalan atas kinerja masa lalu dan mendorong karyawan dalam upaya pengembangan di masa mendatang. ${ }^{4}$ Promosi di RSIA Kendangsari Merr Surabaya adalah untuk menempatkan karyawan yang kompeten dan cocok untuk mengisi jabatan yang kosong pada posisi yang lebih tinggi. Promosi diatur dalam SPO rotasi karyawan.

Transfer adalah pergeseran lateral yang menyebabkan perpindahan individu dari satu posisi ke posisi lain. ${ }^{4}$ Transfer karyawan di RSIA Kendangsari Merr Surabaya disebut rotasi karyawan. Rotasi karyawan dilakukan jika ada posisi kosong dan lebih mendesak bagi karyawan untuk diisi, sehingga dapat mengambil karyawan dari unit kerja lain dengan tingkat posisi yang sama. Rotasi diatur dalam SPO rotasi karyawan.

Job posting adalah undangan terbuka untuk semua karyawan dalam suatu organisasi untuk melamar posisi yang kosong. ${ }^{4}$ Job posting di RSIA Kendangsari Merr adalah sistem mencari pekerja yang sangat terampil untuk mengisi posisi kosong dengan memberikan peluang bagi semua karyawan yang tertarik. Semua karyawan yang tertarik mengisi posisi mengirimkan aplikasi untuk mengikuti seleksi internal.

Job bidding lebih efektif apabila metode ini merupakan bagian dari program pengembangan karir di mana karyawan dibuat sadar akan peluang yang tersedia bagi semua karyawan dalam organisasi. ${ }^{4}$ Tawaran pekerjaan tidak dilakukan di RSIA Kendangsari Merr Surabaya karena belum diatur dalam kebijakan atau pedoman penerimaan staf di unit SDM. Job bidding ini dapat menjadi rekomendasi karena dapat dilakukan di RSIA Kendangsari Merr Surabaya dengan menawarkan tawaran pekerjaan kepada karyawan yang kompeten dengan pengembangan karir untuk memenuhi spesifikasi tertentu yang dibutuhkan pada posisi yang akan ditempati, karyawan harus melalui pelatihan dan pengembangan keterampilan. Selain bermanfaat untuk motivasi dan pengembangan karir SDM, ini juga meminimalkan biaya rekrutmen dan seleksi yang bersumber dari organisasi eksternal.

Iklan adalah bentuk paling umum dari sumber rekrutmen eksternal. Organisasi mengiklankan posisi kosong pada media cetak dan media elektronik untuk mengakses kumpulan pelamar yang lebih besar. ${ }^{4}$ Iklan telah dilakukan di RSIA Kendangsari Merr Surabaya 
untuk merekrut pelamar sesuai dengan posisi yang diminta didistribusikan melalui media sosial atau situs resmi RSIA Kendangsari Merr Surabaya.

E-Recruitment atau rekrutmen online menggunakan alat berbasis web seperti situs internet publik perusahaan untuk merekrut staf. ${ }^{4}$ E-rekrutmen telah dilakukan oleh RSIA Kendangsari Merr Surabaya menggunakan situs web resmi atau media sosial online yang dimiliki. Perbedaan antara iklan dan rekrutmen elektronik adalah bahwa iklan dapat melalui online atau offline, tetapi rekrutmen elektronik hanya melalui online. Karena penerapan metode rekrutmen dengan iklan di RSIA Kendangsari Merr dilakukan secara online, maka menjadi sama dengan e-rekrutmen. Pelamar yang tertarik dapat mengirim surat lamaran kepada RSIA Kendangsari Merr Surabaya secara langsung atau melalui email.

Employee referrals dapat dibuat oleh karyawan dalam organisasi itu sendiri kepada kerabat atau teman profesi, dan lainnya. RSIA Kendangsari Merr dapat merekrut calon karyawan baru melalui rekomendasi dari karyawan internal, yaitu anggota keluarga dari karyawan, teman, atau karyawan perusahaan lain. Calon karyawan tetap harus menjalani proses seleksi menyeluruh untuk menjadi karyawan di RSIA Kendangsari Merr Surabaya.

Kantor tenaga kerja adalah sumber eksternal dari satu jenis pekerja tertentu. Unit SDM RSIA Kendangsari Merr memiliki hubungan kerja dengan departemen tenaga kerja untuk merekrut karyawan baru sesuai dengan lowongan pekerjaan yang diperlukan.

Agen tenaga kerja disebut sebagai penghubung tenaga kerja dengan perusahaan yang membutuhkan karyawan baru, agen tenaga kerja melakukan beberapa penyaringan awal untuk organisasi dan menghubungkan organisasi dengan pelamar. RSIA Kendangsari Merr merekrut melalui agen penempatan tenaga kerja dan telah diatur dalam pedoman penerimaan staf.

Lembaga Pendidikan dan Pelatihan merupakan sumber tenaga profesi baru yang sedang atau telah menyelesaikan pendidikan atau pelatihannya dalam suatu bidang tertentu. Manajer organisasi dapat mengunjungi lembaga pendidikan seperti universitas dan perguruan tinggi untuk menarik mahasiswa, terutama selama tahun terakhir studi untuk melamar posisi yang kosong. Metode rekrutmen ini juga disebut sebagai perekrutan kampus. ${ }^{4}$ Perekrutan karyawan baru oleh RSIA Kendangsari Merr dilakukan di lembaga pendidikan dan pelatihan atau dalam program pelatihan kerja untuk menarik pelamar dari siswa yang baru saja lulus dari pendidikan.

Pencari kerja datang langsung ke departemen SDM untuk mencari pekerjaan, metode ini disebut walks in. Lamaran yang masuk biasanya akan dimasukkan ke dalam arsip sampai ada posisi yang sesuai atau sampai lamaran dianggap cukup lama sehingga 
dianggap valid. Walks in adalah salah satu metode rekrutmen eksternal yang merupakan kumpulan file pelamar yang telah diterima sebelumnya. ${ }^{10}$ Metode walks in telah diatur dalam panduan penerimaan staf dan telah dilakukan di RSIA Kendangsari Merr untuk merekrut calon karyawan baru.

\section{Analisis Seleksi}

Seleksi adalah tahap rekrutmen selanjutnya. Ini melibatkan tidak hanya memilih anggota baru organisasi tetapi juga memastikan bahwa proses seleksi dapat mengatur untuk menarik pelamar yang kompeten dan berkualitas yang cocok untuk pekerjaan itu. ${ }^{7}$ Pada tahap seleksi, manajemen
SDM memilih kandidat terbaik yang sesuai dengan posisi kerja di organisasi dari semua calon yang dikumpulkan pada tahap rekrutmen. ${ }^{11}$ Metode seleksi menurut Maloney, adalah formulir aplikasi, wawancara, cek referensi, tes pra-kerja, dan masa percobaan.

Keputusan manajemen tentang pemilihan karyawan merupakan hal yang sentral dalam operasional organisasi dan menjadi serangkaian hasil yang penting bagi individu, organisasi, dan masyarakat. Proses seleksi dapat terdiri dari penyaringan, tes seleksi, referensi dan pemeriksaan latar belakang, wawancara, pemeriksaan fisik, dan tawaran pekerjaan. ${ }^{4}$

Tabel 2. Perbandingan proses seleksi menurut Darkoh (2014) dengan proses seleksi di RSIA Kendangsari Merr Surabaya

\begin{tabular}{|c|c|c|c|}
\hline Referensi & RSIA Kendangsari Merr & Ada/ tidak ada & Keterangan \\
\hline Screening & Seleksi administrasi & Ada & $\begin{array}{l}\text { terdapat panduan } \\
\text { dan SPO }\end{array}$ \\
\hline Selection tests & $\begin{array}{l}\text { Tes tulis, tes psikologi, dan } \\
\text { kredensial }\end{array}$ & Ada & $\begin{array}{l}\text { terdapat panduan } \\
\text { dan SPO }\end{array}$ \\
\hline $\begin{array}{l}\text { Reference \& background } \\
\text { check }\end{array}$ & Seleksi administrasi & Ada & $\begin{array}{l}\text { terdapat panduan } \\
\text { dan SPO }\end{array}$ \\
\hline Interview & Tes wawancara & Ada & $\begin{array}{l}\text { terdapat panduan } \\
\text { dan SPO }\end{array}$ \\
\hline Physical examination & Tes kesehatan & Ada & $\begin{array}{l}\text { terdapat panduan } \\
\text { dan SPO }\end{array}$ \\
\hline Job offer & $\begin{array}{l}\text { Perjanjian kerja untuk masa } \\
\text { percobaan } 3 \text { bulan }\end{array}$ & Ada & $\begin{array}{l}\text { terdapat panduan } \\
\text { dan SPO }\end{array}$ \\
\hline
\end{tabular}

* Hasil analisis komparatif antara teori dan data sekunder dari unit SDM di RSIA Kendangsari Merr Surabaya

Berdasarkan Tabel 2 dapat dilihat bahwa semua rangkaian proses seleksi untuk calon karyawan baru RSIA Kendangsari Merr Surabaya telah sesuai menurut teori Darkoh dan diatur dalam panduan penerimaan staf dan SPO rekrutmen karyawan. ${ }^{4}$

Tahap selanjutnya setelah mendapatkan kumpulan pelamar adalah penyaringan semua 
lamaran. Screening atau penyaringan lamaran disebut sebagai seleksi administratif. Seleksi administrasi di RSIA Kendangsari Merr Surabaya didasarkan pada kelengkapan file lamaran dengan mempertimbangkan kualifikasi posisi yang diperlukan. Persyaratan administrasi yang harus dipenuhi untuk calon karyawan baru untuk tenaga non-medis meliputi 1 lembar foto berwarna 4x6, 1 lembar fotokopi KTP, surat lamaran, curriculum vitae, dan fotokopi ijazah terakhir (diutamakan yang dilegalisir). Sedangkan untuk staf medis harus dilengkapi dengan Surat Tanda Registrasi (STR) aktif dan akreditasi minimal B untuk perguruan tinggi.

Seleksi administratif juga berfungsi untuk pemeriksaan referensi dan latar belakang. Berdasarkan kelengkapan file lamaran yang diusulkan dapat menjadi titik pertimbangan untuk RSIA Kendangsari Merr Surabaya karena sebagai bukti spesifikasi dan kelebihan yang dimiliki oleh pelamar. Misalnya, lamaran dilengkapi dengan akreditasi universitas, sertifikat pengalaman kerja, atau sertifikat penting dari pelatihan yang telah diikuti yang mendukung keahliannya.

Pelamar yang lulus seleksi administrasi dipanggil untuk menghadiri tes seleksi berikutnya. Tes seleksi adalah instrumen yang digunakan untuk membuat keputusan tentang calon karyawan. Ada sejumlah metode yang digunakan organisasi untuk menentukan apakah pelamar memiliki potensi untuk berhasil pada pekerjaannya. Tes seleksi digunakan untuk mengidentifikasi keterampilan pelamar yang tidak dapat ditentukan dalam proses wawancara. Dengan menggunakan berbagai metode pengujian, pelamar dinilai berdasarkan bakat, kepribadian, kemampuan, kejujuran, dan motivasi. Tes seleksi yang dirancang dengan benar adalah memiliki standar, andal, dan valid dalam memprediksi keberhasilan pelamar dalam pekerjaan.

Seleksi sebagai proses pengumpulan informasi untuk tujuan mengevaluasi dan memutuskan siapa yang akan dipekerjakan untuk kepentingan individu dan organisasi dalam jangka pendek dan panjang. Seleksi memilih dari banyak pelamar menjadi kandidat yang cocok untuk mengisi posisi. ${ }^{13}$

Setelah tes administrasi, diikuti oleh tes wawancara dan tes tulis khusus untuk calon perawat. Tes wawancara dilakukan oleh kepala divisi SDM \& hukum dan kepala divisi yang terkait di mana posisi karyawan baru diperlukan. Setidaknya setiap pelamar diwawancarai tiga kali oleh tiga orang yang berbeda sehingga menjadi pertimbangan untuk mengikuti tahap seleksi berikutnya. Pelamar yang lulus tes tulis dan tes wawancara diberitahu untuk mengikuti tes psikologi. Tes psikologi dilakukan oleh lembaga pengujian psikologis yang telah bekerja sama dengan RSIA Kendangsari Merr Surabaya. Hasil tes psikologi diinformasikan ke RSIA Kendangsari Merr Surabaya untuk dinilai dan diproses pada 
tahap berikutnya. Pelamar yang lulus tes psikologi dilanjutkan untuk tes kesehatan.

Menurut Chungyalpa, proses seleksi terdiri dari beberapa tahap yang harus dilalui secara berurutan, yaitu seleksi formulir lamaran, wawancara pendahuluan, tes ketenagakerjaan, wawancara kerja, pemeriksaan fisik, seleksi akhir, penempatan dan orientasi. ${ }^{14}$ Tes calon karyawan adalah serangkaian tes yang dilakukan untuk memastikan kualitas dan karakteristik kandidat potensial. Tujuan utama dari tes calon karyawan adalah untuk mencocokkan kemampuan fisik, mental dan temperamental seseorang dengan persyaratan pekerjaan. Wawancara kerja adalah metode paling umum untuk merekrut karyawan baru dan banyak digunakan oleh semua organisasi. Tujuan utama wawancara kerja adalah untuk memastikan kecocokan kandidat dan memberikan kesempatan bagi organisasi untuk mengenal kandidat yang lebih baik, terdiri dari motivasi, ambisi, prospek, dll. ${ }^{14}$

Tes psikologis adalah bagian dari tes calon karyawan baru yang hasilnya juga dipertimbangkan dalam memilih calon karyawan. Tahap selanjutnya setelah tes psikologi adalah penentuan hasil seleksi dan panggilan calon karyawan yang dipilih. Setelah dipanggil, calon karyawan harus melakukan pemeriksaan kesehatan. Tes fisik atau kesehatan sangat penting karena lokasi pekerjaan di rumah sakit dan fokus layanan pelanggan adalah untuk kesehatan pelanggan, sehingga pemeriksaan kesehatan diperlukan terutama untuk staf medis yang bersentuhan langsung dengan klien.

Setelah melewati tes kesehatan pada proses seleksi di RSIA Kendangsari Merr Surabaya, keputusan seleksi dibuat untuk calon karyawan terpilih dengan perjanjian kerja untuk masa percobaan 3 bulan. Khusus untuk staf medis sebelum perjanjian masa percobaan 3 bulan harus melalui kredensial terlebih dahulu.

Menurut Chungyalpa, tahap akhir dari proses seleksi adalah seleksi akhir, penempatan dan orientasi. ${ }^{14}$ Pada akhir seleksi, calon karyawan diterima untuk bekerja dan perjanjian masa percobaan bekerja, yang umumnya selama tiga sampai enam bulan. Berdasarkan periode uji coba, evaluasi kerja dilakukan dan perjanjian kerja dilanjutkan untuk periode waktu yang lebih lama.

Penilaian kinerja di RSIA Kendangsari Merr Surabaya adalah evaluasi apakah karyawan memenuhi syarat untuk melanjutkan perjanjian kerja di masa mendatang. Penilaian kinerja dilakukan oleh atasan langsung dari karyawan, dinilai setelah masa percobaan dan setahun sekali selama karyawan bekerja.

Khusus untuk staf medis atau dokter harus melalui proses kredensial oleh komite medis di RSIA Kendangsari Merr Surabaya. Untuk kredensial staf perawat dilakukan oleh komite keperawatan. Untuk staf medis lainnya juga dilakukan kredensial oleh komite staf medis lainnya. Petugas kesehatan lainnya 
termasuk analis medis, apoteker, ahli gizi, rekam medis, dan sanitarian.

Kredensial staf medis mencakup berbagai kegiatan baik di tingkat individu maupun institusi. Kredensial adalah istilah yang diterapkan pada proses yang digunakan untuk menentukan bahwa seorang individu, program, institusi, atau produk telah memenuhi standar yang ditetapkan oleh agen (pemerintah atau non-pemerintah) yang diakui memenuhi syarat untuk melakukan tugas medis. ${ }^{15}$

Kredensial merupakan penilaian terstruktur yang menunjukkan keandalan dalam menilai karyawan dengan potensi peningkatan kinerja untuk pekerjaan kompleks seperti dokter atau staf medis lainnya. ${ }^{16}$

Seleksi adalah proses memilih individu yang memiliki kualifikasi yang relevan untuk mengisi pekerjaan di suatu organisasi. Seleksi lebih dari sekedar memilih kandidat terbaik. Seleksi adalah upaya untuk mencapai keseimbangan terbaik antara apa yang dapat dan ingin dilakukan oleh pelamar dan apa yang dibutuhkan oleh organisasi. Pentingnya seleksi adalah memilih karyawan yang tepat karena tiga alasan utama yang terdiri dari kinerja,

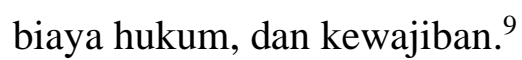

RSIA Kendangsari Merr Surabaya memiliki otoritas penuh dalam menentukan pelamar mana yang terbaik untuk diterima sebagai calon karyawan. Namun, selama proses rekrutmen dan seleksi, pelamar juga memiliki hak untuk mengundurkan diri karena tidak ada perjanjian kontrak kerja dengan organisasi. Berbagai kendala juga perlu dipertimbangkan dalam proses rekrutmen dan seleksi. Misalnya, dari pelamar yang telah mengumpulkan lamaran, tidak semuanya dapat mengikuti proses seleksi karena persyaratan administrasi yang tidak lengkap atau ketidakcocokan dengan spesifikasi yang diperlukan. Oleh karena itu, upaya perekrutan yang lebih besar diperlukan untuk mengumpulkan pelamar sebanyak mungkin dengan kualifikasi yang sesuai. Proses rekrutmen dan seleksi membutuhkan biaya yang tidak kecil dan tidak singkat, sehingga pelaksanaannya perlu pertimbangan yang tepat.

Prosedur rekrutmen dan seleksi di RSIA Kendangsari Merr Surabaya ditulis dalam SPO yang sama yang berisi empat alur seleksi yang berbeda yang terdiri dari alur seleksi untuk karyawan non-medis, staf medis atau dokter, perawat, dan staf medis lainnya. SPO seharusnya dapat memaparkan dengan jelas tentang prosedur khusus dengan menggunakan kalimat pendek dan kata kerja yang mudah dipahami. ${ }^{17}$ Sehingga $\quad$ SPO di RSIA Kendangsari Merr Surabaya lebih cocok sebagai panduan.

SPO perlu dibuat secara terpisah karena setiap prosedur memiliki tujuan khusus tertentu. Misalnya SPO rekrutmen calon karyawan baik untuk staf medis maupun untuk staf non-medis di RSIA Kendangsari Merr Surabaya. Selain itu, prosedur untuk seleksi staf non-medis memiliki SPO sendiri, yang juga 
berlaku untuk prosedur seleksi untuk staf medis seperti dokter, perawat, dan staf medis lainnya sehingga memiliki SPO khusus.

Evaluasi pelaksanaan rekrutmen dan seleksi di RSIA Kendangsari Merr perlu dilakukan untuk mengetahui efektivitas dan efisiensi pelaksanaannya. Hasil evaluasi dapat menjadi referensi dalam merencanakan proses rekrutmen dan seleksi mendatang.

\section{SIMPULAN DAN SARAN}

\section{Simpulan}

Pelaksanaan rekrutmen dan seleksi di RSIA Kendangsari Merr Surabaya sesuai dengan referensi yang ada. Metode rekrutmen di RSIA Kendangsari Merr telah sesuai dengan referensi tetapi ada satu metode rekrutmen yang belum diterapkan di RSIA Kendangsari Merr, yaitu job bidding. Job bidding atau penawaran kerja dapat menjadi rekomendasi yang dapat dilaksanakan di RSIA Kendangsari Merr Surabaya dengan memberikan penawaran kerja kepada karyawan yang kompeten seiring dengan pengembangan pekerjaan yang harus dilewati oleh karyawan. Dengan metode ini, karyawan potensial untuk bersaing secara sehat dan meningkatkan motivasi dalam bekerja sehingga mengalami pengembangan. Proses seleksi di RSIA Kendangsari Merr Surabaya telah sesuai dengan yang ada dalam referensi dan diatur dalam panduan penerimaan staf dan SPO rekrutmen karyawan baru.

\section{Saran}

Masukan yang dapat diberikan adalah membuat perbaikan dan penyesuaian pada SPO rekrutmen dan seleksi, agar sesuai dengan panduan untuk membuat SPO sehingga akan lebih mudah bagi pembaca untuk memahami. Selain itu, SPO untuk rekrutmen calon karyawan baru dibuat secara terpisah dengan SPO seleksi. SPO untuk seleksi calon karyawan baru juga dibuat khusus untuk staf non-medis dan staf medis, yang terdiri dari perawat, dokter, dan staf medis lainnya.

\section{REFERENSI}

1. Ekowoabo, J. O., Ikeije, U. U. and Ufoma, $\mathrm{N}$. 'The Impact of recruitment and Selection Criteria on Organizational Performance', Journal of Chemical Information and Modeling, 2015. 3(2), pp. 22-33. doi: 10.1017/CBO9781107415324.004.

2. Hu, F. 'The Research of Design of Human Resource Recruitment System Based on the Total Relationship Flow Management Theorems', Journal of Human Resource and Sustainability Studies, 2014. 2(December), pp. 196-200. Available at: http://dx.doi.org/10.4236/jhrss.2014.24019.

3. Tomčíková, L. 'The effective recruitment and selection practices of organizations in the financial sector operating in the Slovak republic', eXclusive e-JOURNAL, homepage, 2016. pp. 1339-4509. Available at: http://www.exclusiveejournal.sk.

4. Darkoh, M. A. Employee Recruitment and Selection Practices in the, Kwame Nkrumah University of Science and Technology. Kwame Nkrumah University of Science and Technology. 2014. 
5. Argue, M. The Importance of the Strategic Recruitment and Selection Process on Meeting an Organisations Objectives '. Mary Argue Master of Business Administration General Management Dublin Business School May 2015. Dublin Business School. 2015.

6. Urbancová, H., Stachová, K. and Stacho, Z. 'Methods of recruitment in the Czech and Slovak organizations', Acta Universitatis Agriculturae et Silviculturae Mendelianae Brunensis, 2015. 63(3), pp. 1051-1060. doi: 10.11118/actaun201563031051.

7. Kamran, A., Dawood, J. and Hilal, S. Bin 'Proceedings of the Ninth International Conference on Management Science and Engineering Management', 2015. 362(May). doi: 10.1007/978-3-662-472415.

8. Karthiga, M. ., Karthi, D. . and Balaishwarya, M. 'Recruitment and Selection Process', International Journal of Scientific and Research Publications, 2015. 5(4), pp. 1-4. Available at: www.ijsrp.org.

9. Gupta, A. K. and Kumar, S. 'A Study On Recruitment \& Selection Process With Reference', ResearchGate, 2014. (November), pp. 2-7. doi: 10.13140/2.1.2424.0320.

10. Rahaman, A. 'Employees' Perception of Recruitment and Selection Practices in Local Companies', International Journal of Ethics in Social Sciences, 2016. 4(1), pp. 165-176. Available at: http://www.crimbbd.org/wpcontent/uploads/2016/11/14.-Md.Atikur.pdf.

11. Ivanova, A. Analysis of The Processes of Human Resource Management. Case Fashion Unit OY. Centria University of Applied Sciences. 2015.

12. Maloney, T. R. Employee Recruitment and Selection: How To Hire the Right People, Cornell University Ithaca, NY. 2011.

13. Onyeaghala, O. and Hyacinth, M. 'Effects of Employee Selection Process on Productivity in the Public and Private Sectors: A Case of Benue State', Business and Economics Journal, 2016. 7(4), pp. 18. doi: 10.4172/2151-6219.1000273.

14. Chungyalpa, W. 'Best Practices and Emerging Trends in Recruitment and Selection', Journal of Entrepreneurship \& Organization Management, 2016. 5(2), pp. 1-5. doi: 10.4172/2169-026X.1000173.

15. Needleman, J. et al. 'Nurse credentialing research frameworks and perspectives for assessing a research agenda', National Academy of Science, 2014. pp. 1-12. Available at: https://nam.edu/wpcontent/uploads/2015/06/CredentialingRes earchFrameworks.pdf.

16. Staren, E. 'Beyond credentialing in physician selection: Application of an instrument that measures behavioral aptitude', Patient Experience Journal, 2014. 1(2), pp. 26-35. Available at: http://pxjournal.org/journal/vol1/iss2/7.

17. NC Cooperative Extension. How to Write Standard Operating Procedure (SOP). 2014. Available at: https://ncfreshproducesafety.ces.ncsu.edu/ wp-content/uploads/2014/03/how-to-writean-SOP.pdf?fwd=no.

18. Opayemi, A. S. 'Perception of selection interview, selection test and employee performance: An empirical analysis', Journal of Public Administration and Policy Research, 2013. 5(4), pp. 95-101. doi: 10.5897/JPAPR12.006. 